\title{
How different are Australian ecosystems and ecologists?
}

\section{from Mark Westoby}

IN THE years between sabbaticals, the thinking of Australian ecologists can become developed - fixed, even - to the point where their ideas cannot be driven extinct just because they are inconsistent with what the fashionable majority in the northern hemisphere thinks. That is one possible reason why there have been so many influential Australian ecologists. But another possible reason is that Australian ecosystems are themselves different; to have experienced them is to know that the textbooks are wrong. Last year's symposium of the Ecological Society of Australia* was on that theme.

A central question in ecology is whether the general properties of assemblages of organisms are determined by the presentday environment, or whether they vary idiopathically depending on accidents of the biota's evolutionary history. Can ecologists understand ecosystems, or do we have to hand the job over to palaeontologists? Because Australia's biota has such a separate evolutionary history from the rest of the world, comparisons between Australia and elsewhere are natural experiments on this issue.

Many contributors at the meeting concluded that Australian assemblages are different - but that the differences arise from under-appreciated special properties of the Australian environment, not from evolutionary history. For example P.S. Lake (Monash University) pointed out that the eucalypt leaf-fall, which drives the food-chains of forest streams, arrives during summer while the water is warm, instead of being concentrated in autumn. A.V. Milewski and R.M. Cowling (Western Australian Institute of Technology) compared sclerophyll scrublands in western Australia and South Africa, looking at vegetation on several soil types within each continent. Features such as pollination and seed-dispersal spectra, as well as plant growth forms and leaf shapes, were influenced by soil type. Therefore comparisons between continents ideally need to be on precisely matched soils - but different continents might not contain precisely matched environments. R.J. Whelan (University of Wollongong) contrasted regeneration after fire in Florida and western Australia. In western Australia, many species have their dormancy broken by fire, and early regeneration is a flush of seedlings. In Florida, early regeneration is all vegetative, leading to flowering, production of non-dormant

*'Are Australian Ecosystems Different?', Sydney, 28-29 August 1984. The proceedings will be published by the Society in early 1985 and distributed by Blackwelt Scientific. seeds, and a flush of seedlings in the second year. Whelan argued that reliance on seeds, which are made germinable by fire, is only possible when a reliable rainfall season follows the fire season, as in western Australia.

Conclusions of this type are congenial for Australian ecologists: they mean that more research is needed in Australia. Nevertheless some ecologists were willing to emphasize how similar assemblages on different continents could be once one looked behind the taxonomy. B. Rice (unaffiliated) summarized patterns of local richness in plant species. The same vegetation types that are rich in species on one continent can be poor on another. Available data do not show any clear difference in species richness between different continents within a vegetation type. Presentday environment therefore seems to be a much more important influence than evolutionary history on local richness in plant species. Several contributors described cases where they believed evolutionary history had made a fundamental difference to Australian ecosystems. For example, P.C. Heyligers (CSIRO) and J.D. Sauer (University of California, Los Angeles) independently proposed that Australia lacked an effective sand-binding plant on foredunes, with far-reaching consequences for landforms and vegetation in coastal areas. H.A. Ford (University of New England) suggested that bird pollination was common in Australia in compensation for the lack of social bees.

Methodology loomed large. It had, for example, been thought that insect herbivores take a larger proportion of leaf production in Australian forests than elsewhere. C.D. Ohmart (CSIRO), for eucalypt forests, and M. Lowman (University of New England,Armidale), for rain forests, argued that this was an artefact of using different or poor methods. A.J. Underwood and P.G. Fairweather (Sydney University), drawing on case histories from the study of intertidal communities, illustrated how different conclusions can flow from differences in study design or in the attitudes of investigators.

An unusually wide range of organisms and enviroments were considered at the meeting. This made it possible to go beyond a simple 'yes' or 'no' to the question of whether ecosystem properties are convergent. It seems clear that many ecosystem properties do converge, provided the environments are similar. But some quite subtle differences between environments can be important, and we are beginning to learn what differences to look for. And just occasionally, as in the case of plants that bind sand into foredunes, the presence or absence of an organism with a particular way of life can result in fundamental changes for the rest of the ecosystem.

Mark Westoby is in the School of Biologica Sciences at Macquarie University, North Ryde, NSW 2113, Australia.

\section{Evolutionary biology}

\section{Group selection and the sex ratio}

\author{
from Paul H. Harvey, Linda Partridge and Len Nunney
}

A DEEPER understanding of evolutionary processes often comes from looking at the same problem in more than one way ${ }^{1}$. One problem that has benefited from this approach is that of explaining the femalebiased sex ratio often found in hymenopteran (bee, ant, wasp) and mite populations $\mathrm{s}^{2,3}$.

In 1967, W.D. Hamilton pointed out that an unequal allocation of parental resources to sons and daughters should evolve under certain population structures $^{2}$. He produced a simple model to illustrate the process. Consider a population consisting wholly of fertilized females that come together in groups to lay their eggs. The young from the several clutches laid together mate randomly among themselves before the males die and the females disperse to form the new population in the next generation. Under those circumstances females investing either equally in sons and daughters or more in sons than in daughters would leave fewer offspring than those producing an appropriately female-biased sex ratio.

Hamilton $^{2}$ suggested that a femalebiased sex ratio was favoured because of competition for mates among siblings of the same sex - 'local mate competition'. In practice, sons are more likely to compete for mates than are daughters, because the reproductive success of a daughter is often limited by the number of eggs she can produce, whereas that of a son is limited by the number of mates available to him. If the sons of a single female compete with each other for mating opportunities then, for example, an isolated female need only produce a single son, provided that he is able to fertilize all of his sisters. The production of additional sons is wasted because they do not produce additional grandchildren, whereas additional daughters do, because production of grandchildren is essentially limited by eggs and not sperm. The expectation of a female-biased sex ratio holds in Hamilton's model even when more than 